\title{
Energy conversion in motor vehicles
}

The portfolio of the automotive market appears more and more low-emission and zero-emission propulsions in vehicles. This is the result of measures taken to limit or even eliminate the emission of harmful substances into the atmosphere generated by vehicles. The article covers issues related to energy conversion in automotive drive systems currently offered by automotive manufacturers. Standard, hybrid, hybrid plug-in, electric and fuel cells drive system were analyzed. Attention was drawn to the chain of energy transformations related to each of the analyzed drive systems. The efficiency of the presented vehicle drive systems was analyzed. General conclusions were formulated regarding the method of analyzing energy changes related to the operation of automotive propulsion systems. The article reviewed selected author's own works on hybrid and hydrogen propulsion.

Key words: passenger vehicle propulsion systems, chain of energy transformations, efficiency of energy conversion

\section{Introduction}

For over 130 years, heat engines have been the basic and practically dominant source of power for all types of vehicles. In the case of means of land and water transport, these are mainly piston internal combustion engines, while means of air transport are mainly driven by flow engines. The basic feature of the above-mentioned sources of propulsion is the necessity to use natural, non-renewable energy resources necessary for heat generation. This has specific consequences related to the consumption of air needed to release energy in the oxidation process and, consequently, its impact on the natural environment. It is important to use the same air resources, which are necessary both for the respiratory functions of humans and other living organisms, and for the implementation of many industrial processes, including the functioning of modern heat engines. The final effect is the transformation of the atmospheric air into combustion products containing components that are toxic to living organisms and greenhouse gases, and the average temperature value in areas of human activity is increased. Therefore, the mentioned processes are strictly dependent on the number of population and economic activity, including the number of used vehicles powered by heat engines. They are also dependent on the energy consumption of technological processes necessary to produce fuels from energy resources. Taking into account the mass scale of the use of means of transport, a lively discussion about the past sources of propulsion of motor vehicles has been going on in the world for several years. Its main areas are conducted, on the one hand, in terms of energy expenditure necessary to meet human transport needs, and on the other hand, in terms of environmental burden with direct and indirect effects of the use of propulsion sources of a certain type. It is well known that any type of energy use entails a change in the overall energy balance of the globe. Therefore, the aim of contemporary development works on the future of vehicle propulsion sources is to develop a new propulsion system considering the chain of energy transformations that directly and indirectly affect the environment. In this context, the electric drive of the vehicle, with the generator in the form of a stack of fuel cells, is currently a very advantageous and viable proposition in relation to standard propulsion sources. The most experienced in the construction of this type of vehicles is the Toyota company, which in 1992 started the first work on a FCV (Fuel Cell Vehicle) powered by fuel cells, launching a serial vehicle called Toyota Mirai in 2014. Currently, following Toyota, vehicles of this type are also offered by other vehicle manufacturers (Honda, Hyundai) [9].

It should be mentioned though that before starting work on this latest proposal from the automotive industry, work was carried out on the creation and implementation for mass production of vehicles with hybrid, hybrid plug-in propulsion and purely electric vehicles with traction batteries.

A hybrid propulsion system has three main configurations, namely serial, parallel, and serial-parallel. In a serial hybrid system topology, the internal combustion engine (ICE) drives a generator which electrical power output is combined with the power coming from the electrical storage and then transmitted through an electric DC-bus to an electric motor (EM) driving the wheels. In parallel hybrid system topology, the combined power is mechanical rather than electrical, in which the ICE and the EM are connected to a torque coupling such that their torque is combined and then transmitted to the wheels using a conventional driveshaft and possibly a differential gear. A serial-parallel hybrid system, also known as a power-split hybrid system, combines the complementary advantages of serial and parallel systems [17].

A plug-in hybrid propulsion system essentially possesses the same configuration as a hybrid propulsion system but with an external electric charging plug, bigger electrical components (i.e. an electric motor and a battery), and a downsized engine. Owing to the high capacity of the electrical components, vehicles with plug-in hybrid propulsion can run in full-electric mode for long periods [17]. The presented topography is based on a parallel hybrid system (Fig. 1).

The purely electric propulsions topology is represented by a battery and fuel cell propulsion. The battery electric propulsion is totally powered by electricity and it does not have any fuel tank to store the fuel. This powertrain consists of large rechargeable batteries to power the vehicles and do not release any harmful gasses to the environment. The battery can be recharged from the grid or from any other external power source by using a socket. In fuel cell propulsion hydrogen is used as fuel. The hydrogen power- 

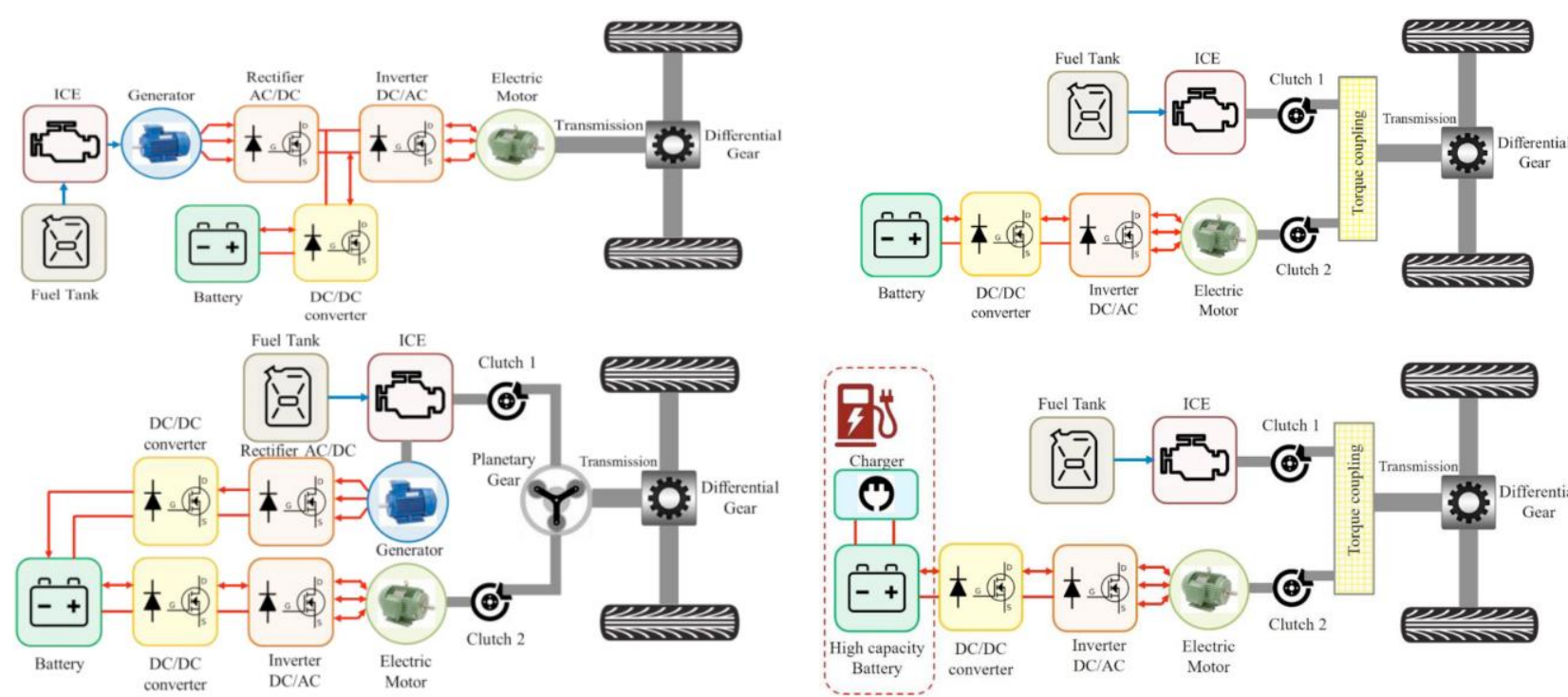

Fig. 1. Types of configuration of hybrid and hybrid plug-in propulsions [17]

train architecture is same as battery electric one. A fuel cell acts as a battery and generates electric power to the motor driving the vehicle [15].

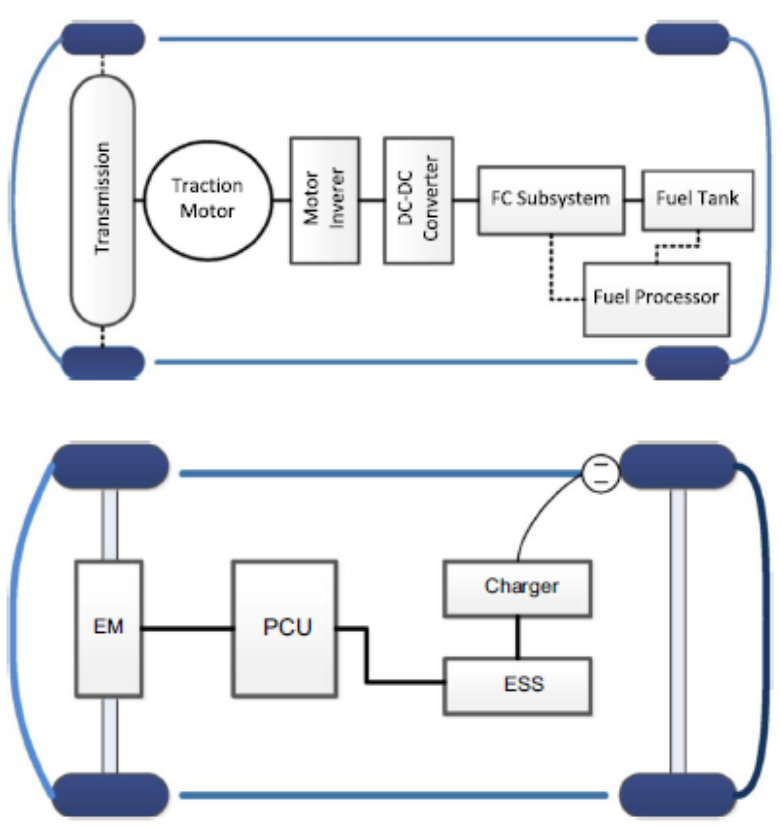

Fig. 2. Configuration battery and fuel cell electric propulsions [7]

\section{Analysis of the energy consumption of modern vehicle drive systems}

Correct analysis of energy consumption in transport should take into account all stages of its processing, starting from obtaining energy resources, transforming them into fuel, and then converting it into mechanical energy that drives the vehicle.

The first vehicles equipped with their own mechanical drive used a piston steam engine. This type of drive was used practically from the mid-nineteenth century to the 1960s, mainly in rail vehicles and water transport, where dimensions, weight of the drive unit and energy storage in the form of hard coal were not a key problem. The chain of energy transformations in this type of drive system was limited to the mining and transportation of hard coal, then the extraction of heat from it in the furnace of the boiler, in which steam was generated and directed to the engine cylinder, and then mechanically transferring the force of the expanding steam to the vehicle wheel drive. Despite the relatively short chain of these changes, the efficiency of energy conversion was very low, because the efficiency of the steam engine itself did not exceed a few percent. This was the main reason for the abandonment of this power source. Another reason was also environmental considerations, as the operation of steam engines usually generated a large amount of soot, which when mixed with water vapor formed a sticky pollutant for the environment. It was especially troublesome at stations and railway routes. It should be mentioned that the decisions to abandon steam engines were made at a time when hard coal resources were easily available and its price on the world markets was very low.

There is an analogy here with the current situation of a piston internal combustion engine, which is currently the dominant source of propulsion for land and water vehicles in the world, and the resources of liquid hydrocarbon fuels are still available at an acceptable price.

Combustion engines generate a third of the mechanical energy from the energy contained in the fuel. The main losses, beyond the effective operating point, are caused by exhaust gas emissions at high temperatures and energy losses in the cooling system. The remainder heat loss includes not only the heat-transfer caused by the convection and radiation on the surface of ICE, but also the heat storage of the system (body, coolant, oil) in the engine compartment during the cycle [5]. Since the internal combustion engine in mobile applications requires connection to a gearbox, its efficiency should also be considered in the energy conversion chain of this type of drivetrain.

Nevertheless, as in the case of the steam engine, the same reasons decided to take steps to seek new solutions for vehicle propulsion systems. The activities are carried out in two directions. 
The first direction is the improvement of the efficiency of the propulsion containing the internal combustion engine through its simultaneous cooperation with the electric motor. Electricity is obtained either from the conversion of the mechanical energy produced by the internal combustion engine or from the conversion of the kinetic energy during vehicle braking. This extends the energy conversion chain and requires the use of additional devices in the form of electrical machines, high-voltage batteries such and voltage converters. Nevertheless, it increases the efficiency of the entire system. In addition, the plug-in system allows to use not only the energy stored in liquid hydrocarbon fuels, but also electricity from the power grid.

The second direction is the replacement of a heat engine as a mechanical energy generator in a vehicle with an electric motor. The source of electricity in this case is either a traction battery or a fuel cell. Energy conversion in a vehicle with a traction battery has a short energy chain. The energy taken from the power grid is stored in the battery and then, after conversion from direct current to alternating current, it is directed to the electric motor and from there through the mechanical transmission to the wheels. In a drive system with a fuel cell, the energy stored in the vehicle is compressed hydrogen. The hydrogen production process itself requires energy. Electricity is generated by a chemical reaction in a fuel cell. The further conversion of energy is identical to that in the battery drive.

\section{Internal combustion engines}

According to the definition, the overall efficiency of an internal combustion engine is the ratio of the effective work measured on the engine shaft to the sum of the supplied heat, which results from the supplied fuel stream and its calorific value.

The overall efficiency of a modern petrol-fueled sparkignition (SI) engine can reach the maximum value of 36 to $40 \%$, while when fueled with natural gas it can reach efficiency even above $40 \%$. This is possible due to the high resistance of natural gas to knocking combustion, which allows the use of a higher compression ratio. The values given refer to the most favorable operating points of the engine, while the average efficiency of an SI engine driving the vehicle in road traffic usually does not exceed $30 \%$.

Contemporary compression-ignition $(\mathrm{CI})$ engine used in vehicle propulsion can achieve an overall efficiency of 42 to $45 \%$, while some stationary engines can achieve efficiency up to $50 \%$. This applies to the most favorable engine operating points, while the average efficiency of a diesel engine driving a vehicle in road traffic is usually up to $35 \%$ [9].

In the chain of energy transformations necessary to drive the vehicle, one should also take into account all energy losses caused by the transmission of torque to the wheels through the drive system components, as well as the energy expenditure related to the production and distribution of hydrocarbon fuels. In the case of motor gasoline and diesel oil, it is energy related to the extraction of crude oil, its transportation and processing in refineries, and then distribution of the finished fuel to filling stations. In this context, it is somewhat more advantageous to supply combustion engines with natural gas, the extraction, transporta- tion and cleaning of which usually requires less energy than the production of liquid hydrocarbon fuels. In terms of energy consumption, the quality of the energy raw material is of great importance, because all types of pollution, e.g. contamination of crude oil with sulfur or phosphorus, significantly increase energy expenditure. The place and method of obtaining energy resources is of similar importance. For example, the production of finished fuel from crude oil obtained in Siberia, due to the climatic conditions and the contamination of the raw material, requires much more energy than from crude oil from Arab countries.

\section{Hybrid drive systems}

Regarding the use of internal combustion engines as a vehicle propulsion source, the introduction of hybrid propulsion systems brought about a significant improvement in energy conversion efficiency. These are usually HEV (Hybrid Electric Vehicle) drive systems, in which the internal combustion engine works with one or two electric machines that play the role of an electric drive motor and a power generator. Research has shown that in real city street traffic, almost $60 \%$ of the distance traveled by a vehicle equipped with a hybrid powertrain is with the combustion engine switched off (Fig. 3).

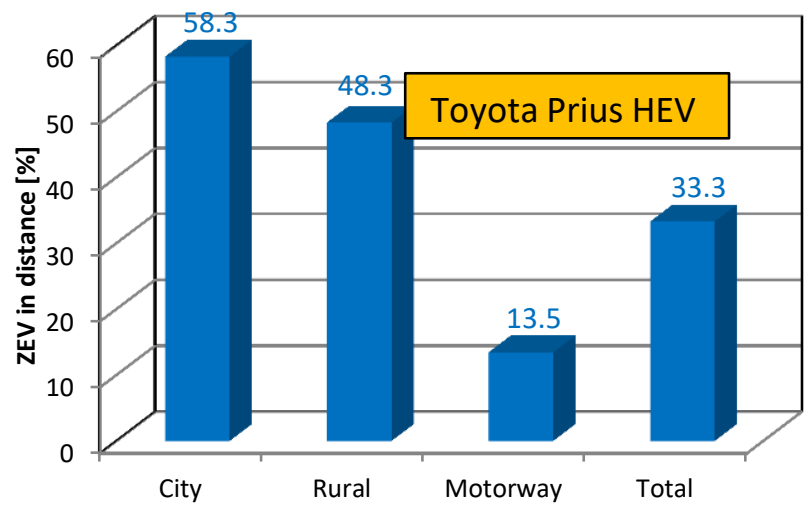

Fig. 3. Proportion of the drive with the combustion engine switched off (ZEV - Zero Emission Vehicle) in relation to the distance traveled in the Real Driving Emissions (RDE) test phases (Toyota Prius HEV) [9]

In some phases of the RDE test, the internal combustion engine is stopped for more than $50 \%$ of its operating time (Fig. 4).

The above results are possible to obtain thanks to the rationalization of the use of energy generated by the internal combustion engine. The braking energy recovery process, which takes place every time the direction of torque transmission changes, using the vehicle's kinetic energy to generate electricity and charge the battery, has the greatest share in this. In fact, only part of the braking energy is recovered due to the limitations resulting from the possibility of rapidly storing a large stream of generated electricity in the battery. For this reason, HEVs use special batteries, where the electric capacity is not the most important parameter, but the ability to frequently, cyclically receive and release a large stream of energy is important. Toyota has been using this type of nickel metal hydride (Ni-MH) battery for many years in its hybrid vehicles, and a new lithi- 
um-ion (Li-Ion) battery with similar properties has been developed for the latest models.

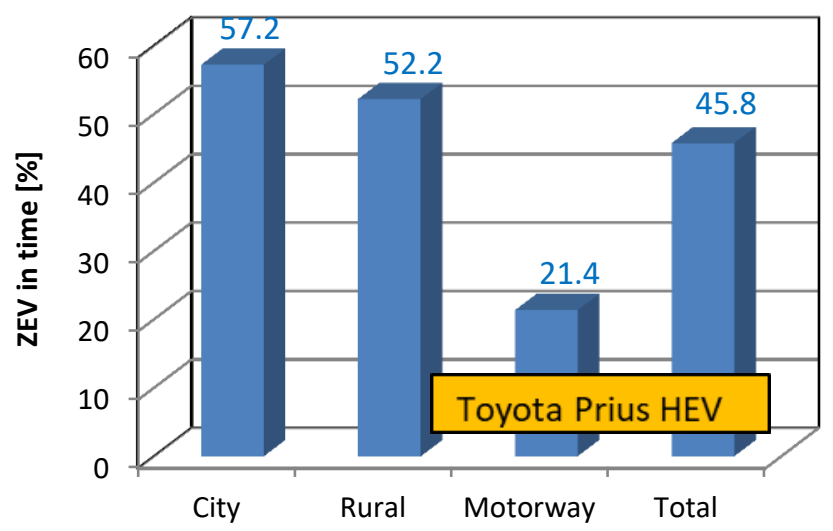

Fig. 4. Proportion of the drive with the combustion engine switched off (ZEV) in relation to the duration of the individual phases of the RDE test (Toyota Prius HEV) [9]

In the latest designs of hybrid drives, the energy recovered during braking accounts for up to $60 \%$ of the electric energy supplying the vehicle drive system. It should be emphasized here that the electricity collected in this way makes it possible to support the internal combustion engine with an electric motor, thanks to which the internal combustion engine can only work in the area of the part of characteristic, in which it develops the greatest efficiency. The support with an electric motor also allows the possibility of using a lower-power combustion engine, optimized for operation in the area of the highest efficiency, to drive the vehicle. Such a solution is e.g. the SI engine operating according to the Atkinson cycle, which allows the use of a high value of the compression ratio, which significantly increases the efficiency, which in this type of engine reaches over $40 \%$.

The efficiency of the hybrid system used in passenger cars is primarily determined by the type of energy management system used. The parallel system is beneficial during city driving because the traction battery is able to support the work of the combustion engine thanks to the frequent possibility of recharging with energy recovered during braking.

The disadvantage of this solution is the inability to assist the internal combustion engine in the event of a low charge of the traction battery. In contrast, the serial arrangement is advantageous in steady travel where the vehicle speed varies within a narrow range. The combination of these two types of systems is a serial-parallel system that enables the internal combustion engine to operate in parallel with the electric motor at a low battery charge and, at the same time, to quickly recharge it. The optimal solution is a structure that connects all the systems and makes it possible to use them in any way depending on the speed and load of the vehicle.

Research using the HEV drivetrain [9] show that the average SOC (State of Charge) value in the drive test is independent of the initial battery state of charge. The battery charging time depending on the initial (differentiated) level of SOC is shown in Fig. 5.

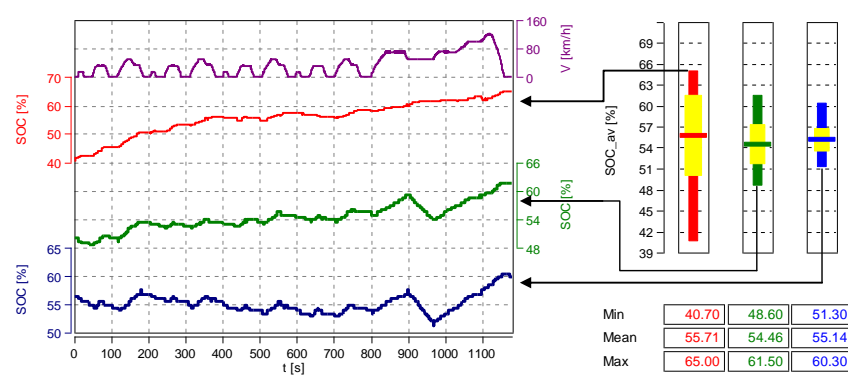

Fig. 5. Initial and average SOC values for various degrees of initial battery discharge and charging conditions during the NEDC test [14]

All the above-mentioned features of the hybrid drive system mean that the efficiency of energy conversion is significantly higher than in standard vehicles powered only by an internal combustion engine. The tests showed that the cost of operational fuel consumption by vehicles equipped with this type of drive system is usually lower by 20 to $40 \%$ compared to a standard vehicle of a similar class. Since the fuel used to power the engine is gasoline as in the case of standard vehicle drive systems, we must also take into account energy losses caused by the production and distribution of this fuel in the overall energy balance. Figure 6 shows the fuel consumption of the HEV (Toyota Prius) in the successive phases of the RDE test measured by the carbon balance method.

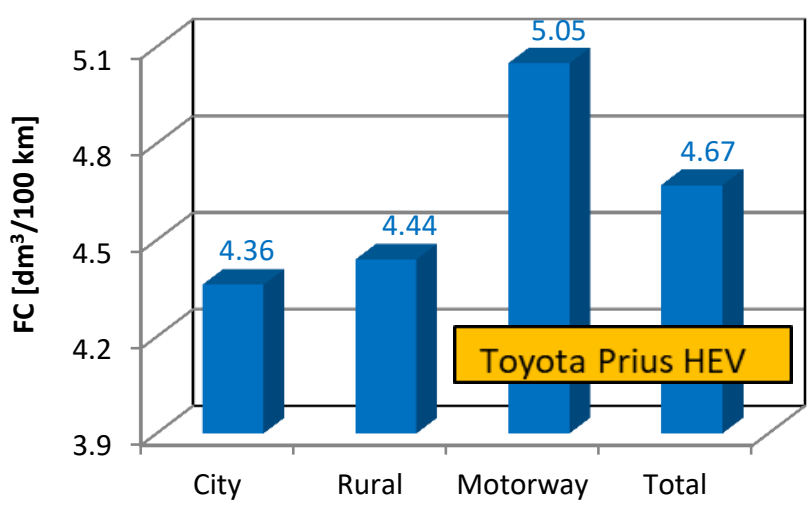

Fig. 6. Fuel consumption in the subsequent phases of the RDE test (Toyota Prius HEV) [9]

\section{Plug-in hybrid drive systems}

A more developed hybrid vehicle drive system is the PHEV (Plug-in Hybrid Electric Vehicle) system, which has a greater potential to increase the efficiency of energy conversion than in classic HEV hybrid vehicles. These vehicles use a Li-Ion battery with a much higher electrical capacity and the possibility of charging from the grid. They offer all the benefits of a hybrid powertrain, including brake energy regeneration. In addition, during proper operation, consisting in regular charging of the battery from the grid, the share of electricity in the vehicle drive is significantly greater than in the standard hybrid drive. This has a positive effect in the form of increasing the efficiency of the drive system and reducing the emission of toxic exhaust gas components, especially during urban operation. In operational tests, the PHEV hybrid drive system shows an advantage over the standard HEV system, but the necessary 
condition is the systematic recharging of the electric battery from the power grid. Figures 7-10 show the results of the PHEV operational tests carried out in the context of fuel consumption and the share of time and distance in which the electric drive is used. The obtained test results are more favorable than for the standard hybrid HEV vehicle.

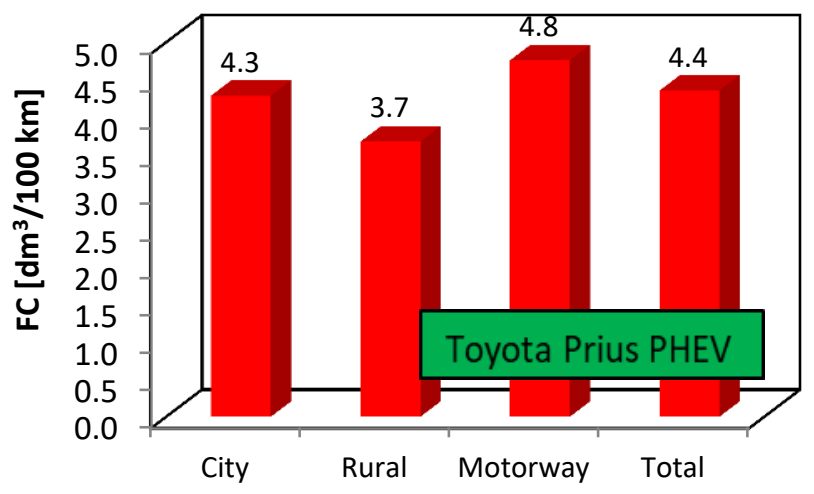

Fig. 7. Fuel consumption in the subsequent phases of the RDE test (Toyota Prius PHEV) [4]

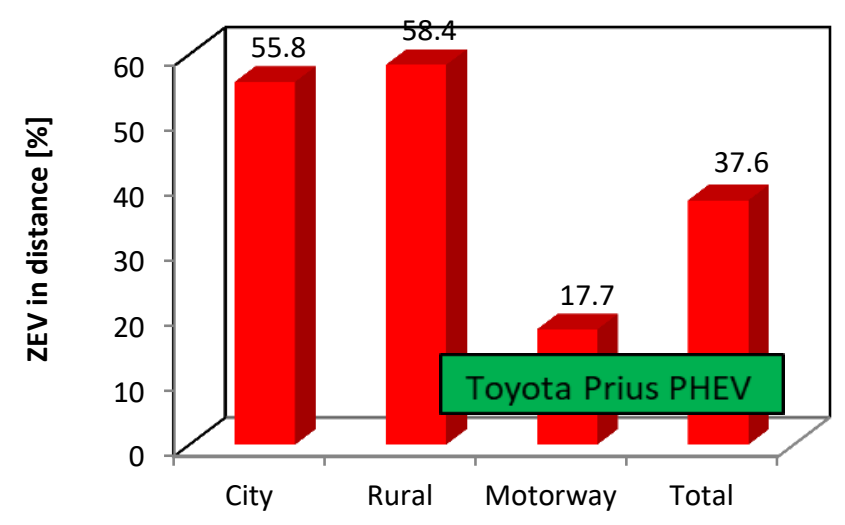

Fig 8. Proportion of the drive with the combustion engine switched off (ZEV) in relation to the distance traveled in the RDE test phases (Toyota Prius PHEV) [4]

An example of an analysis of the operating conditions of Prius plug-in hybrid drive (Fig. 9).

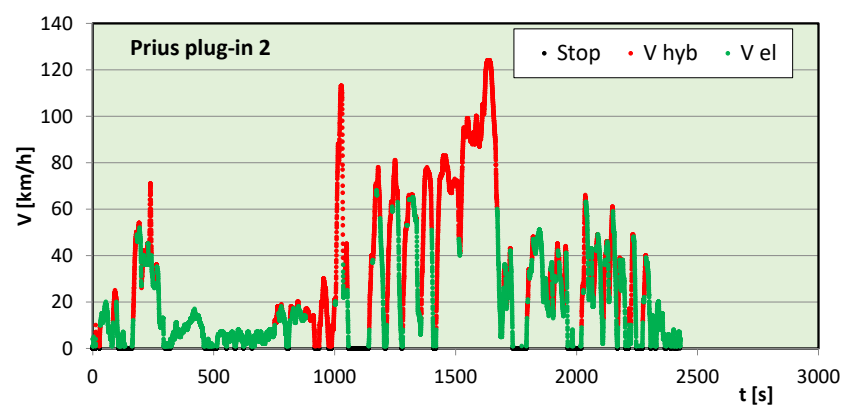

Fig. 9. Operational conditions of vehicles in electric (V el) and hybrid mode (V hyb) [11]

Statistical studies, however, have shown that only a minority of users regularly recharge the traction battery from the grid. The results of research in this area, conducted in three automotive markets, i.e. North America, Europe and
Asia, showed that on average only $7.5 \%$ of users regularly charge their batteries from the power grid. Moreover, some of the vehicles with this type of drive are returned by users to the lessor with a factory-packed set of cables for charging the battery, which means that they operate the vehicle only with the internal combustion engine turned on.

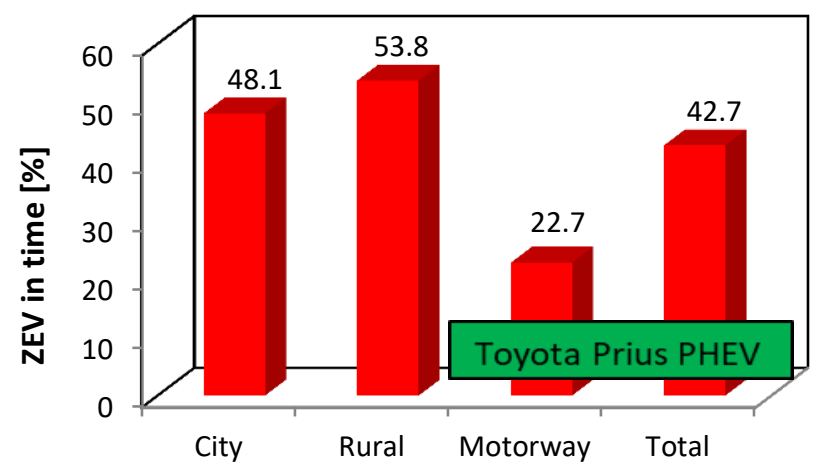

Fig. 10. Proportion of the drive with the combustion engine switched off (ZEV) in relation to the duration of the individual phases of the RDE test (Toyota Prius PHEV) [9]

In drive systems of the PHEV type, depending on the type of energy management used, vehicle operation has different effects in the event of irregular battery charging from the power grid. However, taking into account the large losses caused by energy transformations during this type of operation, the total energy balance of the drive system may turn out to be even less favorable than in standard vehicles powered only by an internal combustion engine.

In the case of a parallel hybrid system, a car with an uncharged traction battery consumes more fuel and generates more toxic exhaust gases compared to the same model with a conventional drive. This is due to the increase in weight of the vehicle by the weight of the traction battery and the inability to support the internal combustion engine by the electric motor. However, when we are dealing with a hybrid drive which, depending on the traffic conditions, works in a serial, parallel or serial-parallel mode, its operating parameters do not differ from a hybrid vehicle without the Plug-in option. The internal combustion engine (Fig. 11) and electric motor (Fig. 12) are running in range of high efficiency. The only downside is the greater weight and dimensions of the electric battery.

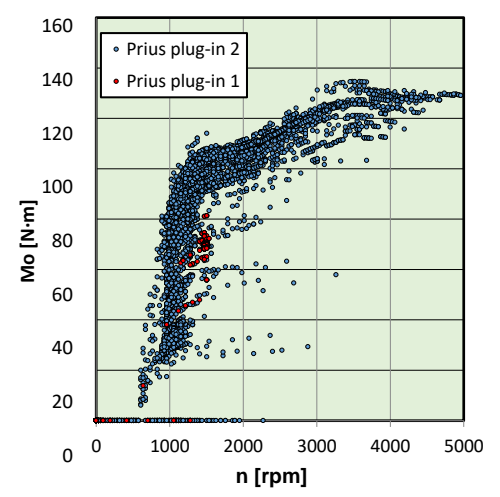

Fig. 11. Operational conditions of the combustion engines of tested hybrid vehicles in urban traffic conditions [3] 


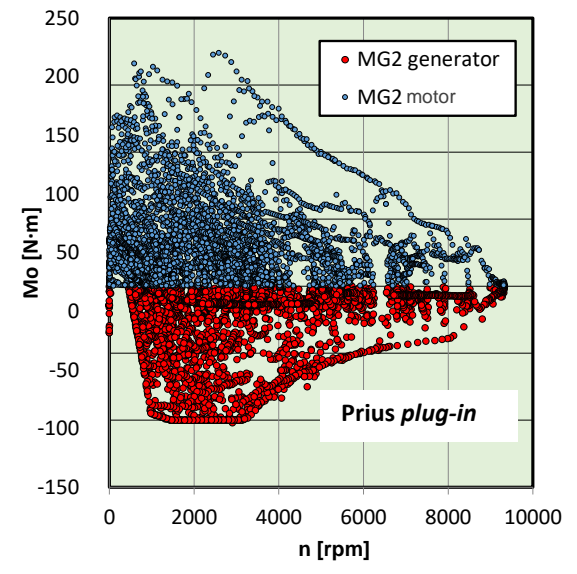

Fig. 12. Conditions of electric motors operation for engine and generator mode of operation [3]

\section{Electric drive systems}

The key problem of vehicles powered by electric motors (BEV - Battery Electric Vehicle), drawing energy only from a set of batteries, is the efficiency of charging the battery and the efficiency of consumption of the electricity stored in the battery by the motor. When charging the commonly used Li-Ion batteries from the power grid, heat losses occur due to the heating of the cells, which requires the use of cooling systems. A similar phenomenon occurs during the transfer of energy to the motor and to other electric devices in the vehicle. The total amount of losses, which is about $12 \%$ of the energy used for charging, depends on the value of the intensity of the flowing electric current, as well as weather conditions. In order to maintain the proper working cycle of the batteries in winter, they should be heated, and cooled intensively in summer. The losses in the electric motor amounting to 2-3\% can be considered very small. Another problem that seriously limits the value of the vehicle is the long battery charging time. In addition, compared to conventional solutions using liquid hydrocarbon fuels, the currently used batteries, mainly of the Li-Ion type, have insufficient capacity to store energy needed to drive the vehicle, in relation to their dimensions and weight. Figure 13 shows the arrangement of the components of a BEV with an electric powertrain (Lexus UX).

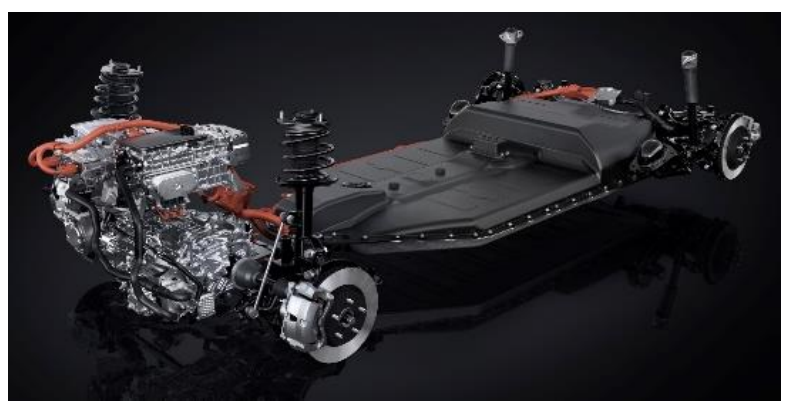

Fig. 13. Arrangement of the components of the electric driveline (Lexus UX) [8]

When analyzing the energy consumption of electric drive systems, one should take into account the source and efficiency of obtaining electricity, as well as losses related to its transmission. When using electricity from thermal power plants that burn non-renewable fossil fuels, the energy balance of such a solution is not very favorable both in terms of energy consumption and environmental impact. Another unfavorable phenomenon is the inability to store electricity for charging the battery, which on a global scale creates problems with planning energy supply to the power grid.

\section{Fuel cells}

According to many opinions, the only real competition for an internal combustion engine is the Fuel Cell Vehicle system, which uses electricity generated on board the vehicle from a stack of hydrogen-powered fuel cells. Compared to an electric drive system that draws electricity from batteries, this type of drive system has much more advantageous features. In the case of fuel cells, there are no restrictions related to the range of the vehicle and the time to refuel hydrogen. The Toyota Mirai was the first FCV sedan to enter the market in series in 2014. It is a medium size car whose range, after fully refueling with hydrogen tanks, is estimated at around 500 to $700 \mathrm{~km}$. The procedure of filling composite tanks with hydrogen is similar to the LPG ( $\mathrm{Li}$ quefied Petroleum Gas) filling procedure and its time is comparable to the time of filling the tank with liquid fuel. The source of the vehicle's propulsion is a $114 \mathrm{~kW}$ electric motor, and this power level provides the performance typical for vehicles of the represented class. The maximum torque generated by the electric motor is $335 \mathrm{Nm}$, which is comparable to torque values achieved by $\mathrm{CI}$ engines, characterized by a high torque value compared to SI engines. It should be emphasized that in electric cars, thus also in the case of FCV, the maximum torque is achieved already starting from zero revolutions per minute. Moreover, with a smaller mass of the drive unit and without harmful emissions for the environment [16]. Figure 14 shows the arrangement of the individual components of the fuel cell driveline (Toyota Mirai).

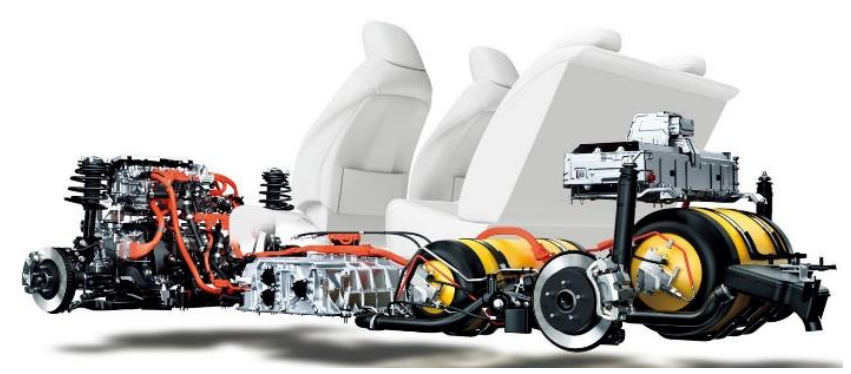

Fig. 14. Arrangement of the components of the fuel cell driveline (Toyota Mirai) [8]

The only waste product discharged into the environment during the operation of the vehicle is water. This can be a problem during operation at negative ambient temperatures, while the developed procedures for washing and drying the cell surface protect the system against freezing. This was confirmed by tests carried out in a thermoclimatic chamber. Figure 15 shows a diagram of temperature changes in individual elements of the drive system with fuel cells (Fuel Cell Stack coolant and air) during tests in a thermoclimatic chamber. 


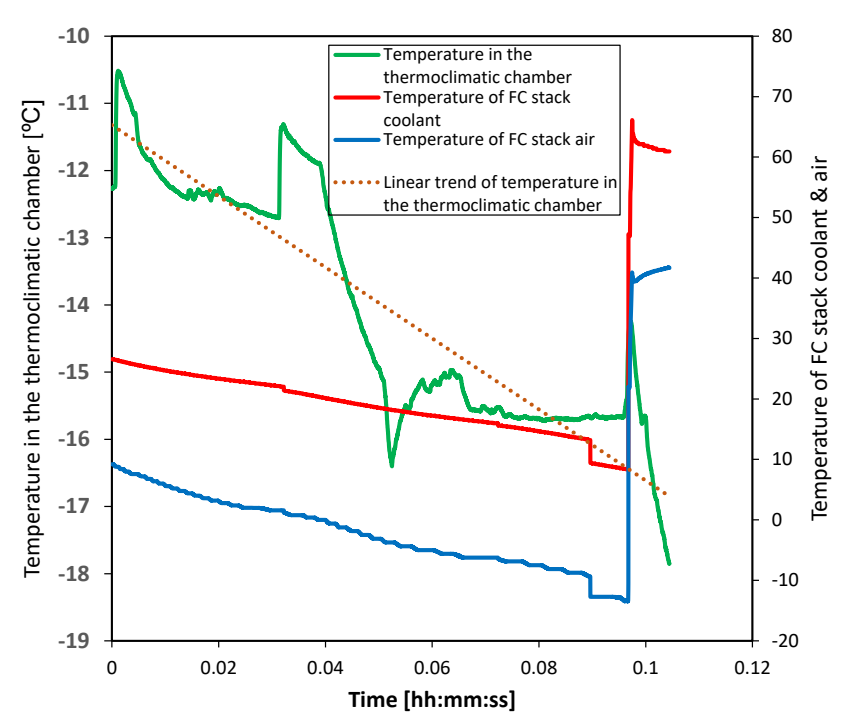

Fig. 15. Temperature of the cooling medium of fuel cells and air in the cell segments during vehicle tests in the thermoclimatic chamber $[1,2]$

A significant advantage of using fuel cells to propel vehicles is the possibility of introducing them to a very wide range of vehicles, including lorries, buses, various types of rail vehicles and a wide range of industrial machinery, such as road, construction or mining machinery. In this context, battery operation for electric vehicles is in no way competitive.

The efficiency of the FCV drive system comes down to determining the efficiency of energy conversion in the fuel cell stack and the efficiency of converting energy transmitted to the electric motor. The fuel cell stack used in the Toyota Mirai model achieves a maximum energy conversion efficiency of $65 \%$. Such high efficiency has been achieved by implementation of three main solutions i.e. reducing the thickness of the electrolyte membrane, humidifying the system using the moisture at the anode and reducing evaporation [6]. The transfer of the energy generated in the stack to the electric motor is achieved with the same efficiency as in the case of BEVs. As with hybrid or electric powertrain vehicles, FCVs use a Brake Energy Regeneration system in which the electrical energy accumulator acts as an energy buffer, storing the recovered energy and then using it to support the operation of the fuel cell stack.

A key issue in assessing the efficiency of energy conversion in FCVs is to consider the energy chain needed to produce hydrogen. This applies to both the method of obtaining hydrogen and its purification to the required purity parameters, amounting to approx. $99.97 \%$.

Currently, hydrogen is available on the market and it is classified according to the method of production. For example, hydrogen, currently used in the refining and chemical industries, is mainly produced by steam reforming of natural gas or coal gasification. Both methods generate $\mathrm{CO}_{2}$ emissions, which is why the hydrogen produced in this way is called gray hydrogen. A transient method for producing hydrogen is its production from fossil fuels, and the resulting carbon dioxide is captured and stored in underground reservoirs. The hydrogen obtained this way is called blue hydrogen. Hydrogen can also be produced by the methane pyrolysis process, in which natural gas is heated to high temperatures to generate hydrogen. The remainder of this process is solid carbon which can be used for other purposes. In this process, large energy expenditure is necessary, and the hydrogen produced by this method is called turquoise hydrogen. The mentioned methods of hydrogen production require a large energy input and generate emissions of carbon dioxide, and often also toxic gaseous components. In addition, they require the use of natural gas or coal, which are a non-renewable fossil fuel, and their extraction in developed countries requires import from distant extraction sites. For this reason, only so-called green hydrogen obtained from renewable energy sources is consider as ultimate fuel to be used in the power units of the FCV type vehicles. It is predicted that water electrolysis, among others, will be used for obtaining hydrogen, while assuming that the electricity required in this process comes exclusively from renewable energy sources.

Currently, the share of green hydrogen in the economy is very small due to high production costs. It is estimated that the current production costs are about three times higher than the costs of producing gray hydrogen, and technological advances in the development of renewable energy sources have reduced these costs by over $50 \%$ in the last decade. It is estimated that by 2040 the cost of producing green hydrogen in Europe will be similar to the cost of producing hydrogen currently used in industry. One should also consider a number of conditions affecting the costs of renewable energy and the investment outlays necessary to obtain it. In Europe, wind, hydro and photovoltaic farms have the largest share in obtaining renewable energy. In some parts of the world, climatic conditions may favor a significant reduction of these costs, such as obtaining energy from photovoltaic farms in countries in the subtropical zone. Taking into account the changing external conditions, which have a significant impact on the costs of electricity production from renewable energy sources and the local conditions and costs of producing green hydrogen directly resulting from it, quantification of the energy transformation chain for FCVs is not an easy task. Moreover, in the last decade, the market of electricity supply in the world from various sources has been changing very dynamically, not allowing for a reliable complete energy balance. Stabilizing this situation and creating a new global energy mix will make it possible to make a clear forecast about the future of vehicle propulsion sources.

\section{Conclusions}

Currently, despite the well-developed production of internal combustion piston engines, which are still characterized by sufficient utility values, and in view of the sufficient availability of liquid petroleum-derived fuels, an intensive search for a new type of drive for industrial vehicles and machines is underway in the world. This was due to a significant change in the criteria for assessing vehicle propulsion sources, which took place especially in the last decade. The basic conditions that currently play a key role and must be met are climate neutrality and high energy conversion efficiency. In this context, the unquestionable recent progress in the development of conventional internal combustion engine drive systems is no longer sufficient. A radical change in this respect, introducing an electric drive to vehicle propulsion, commonly powered by electric cells, is currently impossible, both due to the lack of appro- 
priate infrastructure, limited resources of necessary materials, and clearly limited operational values. An important factor also taken into account are the sources of electricity, which on a global scale are associated primarily with the inefficient combustion process of non-renewable fossil fuels. According to current forecasts, the development of this type of vehicles will take place, but mainly in the sector of urban vehicles, operated in urbanized, richer regions of the world.

A rational, transitional stage in the development of vehicle propulsion sources, which retains all the operational values of standard vehicles, is the introduction of $\mathrm{HEV}$ and PHEV hybrid propulsion systems. Their main advantage is significantly greater efficiency of energy conversion and lower environmental impact. This stage of development will allow the gradual transformation of the car market towards completely new powertrains.

According to many opinions, the only source of propulsion that will replace the currently used internal combustion engines in the long run is a drive system equipped with hydrogen-powered fuel cells. As the operational tests have shown, the utility values and the scope of application of these drive systems are not inferior to modern piston engines. This type of propulsion gives the potential possibility of using renewable energy sources, processed with greater efficiency and guarantees climate neutrality.

\section{Nomenclature}

$\begin{array}{ll}\text { BEV } & \text { Battery Electric Vehicle } \\ \text { CI } & \text { Compression Ignition } \\ \text { FCV } & \text { Fuel Cell Vehicle } \\ \text { HEV } & \text { Hybrid Electric Vehicle } \\ \text { ICE } & \text { Internal Combustiom Engine } \\ \text { Li-Ion } & \text { Lithium-Ion Battery } \\ \text { LPG } & \text { Liquefied Petroleum Gas }\end{array}$

Ni-MH Nickel-Metal Hydride Battery

PHEV Plug-In Hybrid Electric Vehicle

RDE Real Driving Emissions

SI Spark Ignition

SOC State of Charge

ZEV Zero Emission Vehicle

\section{Bibliography}

[1] BRZEŻAŃSKI, M., SZAŁEK, A., SZRAMOWIAT, M. Tests of the vehicle's power unit with fuel cells at a reduced ambient temperature. Combustion Engines. 2019, 179(4), 65-69. https://doi.org/10.19206/CE-2019-410

[2] BRZEŻAŃSKI, M., SZAŁEK, A. Tests of the vehicle's powertrain with hydrogen fuel cells at a low temperature. Proceedings of 8th International Conference on Hydrogen Safety (ICHS2019), 2019 Adelaide, South Australia.

[3] CIEŚLIK, W., PIELECHA, I., SZAŁEK, A. Assessment of parameters of the hybrid drive system in vehicles in urban traffic conditions. Combustion Engines. 2015, 161(2), 14-27.

[4] CIEŚLIK, W., PIELECHA, I., SZAŁEK, A. Indexes of performance of combustion engines in hybrid vehicles during the UDC test. Combustion Engines. 2015, 160(1), 11-25.

[5] DONG, H., FU, J., ZHAO, Z. A comparative study on the energy flow of a conventional gasoline-powered vehicle and a new dual clutch parallel-series plug-in hybrid electric vehicle under NEDC. Energy Conversion and Management. 2020, 218, 113019.

https://doi.org/10.1016/j.enconman.2020.113019

[6] HASEGAWA, T., IMANISHI, H., NADA, M. et al. Development of the Fuel Cell System in the Mirai FCV. SAE Technical Paper 2016-01-1185, 2016. https://doi.org/10.4271/2016-01-1185

[7] HIMADRY, S.D., TAN, C.W., YATIM, A.H.M. Fuel cell hybrid electric vehicles: A review on power conditioning units and topologies. Renewable and Sustainable Energy Reviews. 2017, 76, 268-291.

https://doi.org/10.1016/j.rser.2017.03.056

[8] Materials Toyota Motor Corporation.

[9] Materials Toyota Motor Poland.

[10] MERKISZ, J., PIELECHA, J., BIELACZYC, P. et al. A comparison of tailpipe gaseous emissions from the RDE and WLTP test procedures on a hybrid passenger car. SAE Technical Paper 2020-01-2217. 2020. https://doi.org/10.4271/2020-01-2217

[11] PIELECHA, I., CIESLIK, W., SZALEK, A. Impact of combustion engine operating conditions on energy flow in hybrid drives in RDC tests. SAE Technical Paper 2020-012251. 2020. https://doi.org/10.4271/2020-01-2251

[12] PIELECHA, I., CIEŚLIK, W., SZAŁEK, A. Operation of hybrid propulsion systems in conditions of increased supply voltage. International Journal of Precision Engineering and Manufacturing. 2017, 18(11), 1633-1639. https://doi.org/10.1007/s12541-017-0192-3

[13] PIELECHA, I., CIEŚLIK, W., SZAŁEK, A. The use of electric drive in urban driving conditions using a hydrogen powered vehicle - Toyota Mirai. Combustion Engines. 2018, 172(1), 51-58. https://doi.org/10.19206/CE-2018-106

[14] PIELECHA, I., CZAJKA, J., WISŁOCKI, K. et al. Wpływ stopnia naładowania akumulatorów na warunki pracy napędu hybrydowego w teście NEDC. Technika Transportu Szynowego. 2013, 10.

[15] REDDY, J., NATARAJAN, S. Energy sources and multiinput DC-DC converters used in hybrid electric vehicle applications - A review. International journal of hydrogen energy. 2018, 43, 17387-17408.

https://doi.org/10.1016/j.ijhydene.2018.07.076

[16] TOMAR, M., CHOUDHARY, M., JAIN, D. et al. Performance analysis and economic feasibility of fuel cell vehicles: a perspective review. SAE Technical Paper 2020-012256, 2020. https://doi.org/10.4271/2020-01-2256

[17] TRAN, D., VAFAEIPOUR, M., EL BAGHDADI, M. et al. Thorough state-of-the-art analysis of electric and hybrid vehicle powertrains: topologies and integrated energy management strategies. Renewable and Sustainable Energy Reviews. 2020, 119, 109596.

https://doi.org/10.1016/j.rser.2019.109596

Andrzej Szałek, DEng. - Toyota Motor Poland Company Limited, Warsaw.

e-mail: andrzej.szalek@toyota.pl 